\title{
The effect of herd of origin by year on post-weaning traits of young beef bulls at centralized testing centres in South Africa
}

\author{
K.A. Nephawe ${ }^{\#}$, A. Maiwashe and H.E. Theron \\ ARC-Livestock Business Division, Private Bag X2, Irene 0062, South Africa
}

\begin{abstract}
The effects of herd of origin by year on the average daily gain (ADG), average daily feed intake (DFI), shoulder height (SDH) and scrotal circumference (SCR) of beef bulls at centralized test centres in South Africa were investigated using data of Bonsmara cattle. Data consisted of post-weaning traits of beef bulls tested between 1990 and 2003, with available weaning weight (WWT) and weaning management group information as well as weaning weights of their contemporaries. A multiple-trait animal model including ADG, DFI, SDH and SCR, together with WWT was used. The model for WWT (adjusted to 205 days of age and age of dam by sex of calf classes) included the fixed effect of management group and random effects of direct additive genetic and dam effects, while the model for post-weaning traits included fixed effects of test group and age of the bull at the end of test (fitted as linear and quadratic regressions) and random effects of direct additive genetic and herd of origin by year (HY) effects. Variance components were estimated using REML procedures. Heritability estimates were $0.27,0.34,0.36,0.51$ and 0.46 for WWT, ADG, DFI, SDH and SCR, respectively. The contribution of HY effects to the phenotypic variance of ADG, DFI, SDH and SCR were $9 \%, 10 \%, 6 \%$ and 5\%, respectively. Inclusion of HY effect resulted in the re-ranking of sires, with rank correlations ranging from 0.86 to 0.98 among the top sires, across traits. These results suggest that the $\mathrm{HY}$ effect should be included in the model for the national genetic evaluation of post-weaning traits of beef bulls measured at centralized testing centres in South Africa.
\end{abstract}

Keywords: Beef cattle, genetic evaluation, growth traits, variance components

\#-Corresponding author. E-mail: knephawe@arc.agric.za

\section{Introduction}

The Department of Agriculture initiated the central performance testing of beef bulls (Phase C) in South Africa as early as 1963 . Over the years, young weaner bull calves have been sent to one of the central testing stations where individual feed intakes and body weights are recorded on a weekly basis. Body measurements are also recorded at the completion of the test.

The integrity of the post-weaning central testing programs has been questioned due to concerns regarding pre-test environmental carry-over (Dalton \& Morris, 1978). The main aim of testing bulls in a centralized centre is to compare them fairly under uniform management and environmental conditions. In South Africa, beef cattle are raised in a wide range of environmental and climatic conditions, and thus bulls may come from herds that differ in environmental conditions and management practices. Before commencement of the test the bulls are allowed a four-week (28 days) preliminary period to adapt gradually to the new environment at the testing centre and to the standardized diet. However, studies have indicated that the herd of origin has an important effect on performance of bulls on test despite the adaptation periods (e.g. Collins-Lusweti \& Curran, 1985; Amal \& Crow, 1987; Schenkel et al., 2004). The literature also indicates the existence of a negative environmental correlation between pre-test and test weight gain, indicating compensatory gain on test (e.g. Tong, 1982; Tong et al., 1986; De Rose et al., 1988a).

De Rose et al. (1988b) and Schenkel et al. (2004) argued that the pre-test environmental carry over effect on performance to the test should be accounted for by using a two-trait animal model, incorporating pre-weaning and test performance. The two-trait individual animal model with maternal effects should include pre-test performance in the herd of origin of a bull to address the within-herd-year aspect of the environmental carry-over, which includes those influences that vary within a herd-year, such as maternal effects. The across-herd-year component of the environmental carry-over, which comprises those effects that are generally consistent within herd-years, such as nutritional plane, health, management factors, etc., should 
be accounted for by including the herd-year effect in the model for performance in test centres (De Rose et al., 1988a; Schenkel et al., 2004).

The objectives of this study were therefore to determine the proportion of phenotypic variance accounted for by herd of origin by year effect and to estimate genetic parameters for and amongst weight gain, feed intake, shoulder height and scrotal circumference of young beef bulls at centralized growth test centres in South Africa. Spearman's rank correlations were also computed based on the estimated breeding values to determine the influence of herd of origin by year effect on the genetic evaluation.

\section{Materials and Methods}

Data of Bonsmara cattle participating in the South African National Beef Cattle Improvement Scheme (NBCIS) were used in this study. Measurements of post-weaning traits of young bulls collected at the centralized growth test centres were evaluated.

Bull calves are only eligible for testing if they could qualify for registration (or recording) by the breeders' society concerned. Furthermore, the owner should verify that such bulls have been immunized against anthrax, black-quarter, lumpy skin disease and infectious bovine rhinotracheitis (IBR) two weeks prior to arrival at the testing centre. Immunization against gall-sickness, red water and heart water, although not compulsory, is also recommended. Only bull calves between 151 and 250 days of age at arrival and of which the arrival weight falls within a minimum and maximum range per breed ( $220-270 \mathrm{~kg}$ for Bonsmara) are accepted for testing. On arrival at the testing centre, bulls are given a four weeks (28 days) adaptation period (prior to 1990, for five-weeks) so that they can adapt to the diet and learn to feed from their assigned Calan gates before the commencement of the test. The duration of these centralized tests was originally 20 weeks (140 days), but was shortened to a 16-week (112 days) test-period in 1990, and further reduced to a 12 -week (84 days) test-period in 1999, as recommended by Archer \& Bergh (2000). Bulls are fed from individual troughs using electronic feeder gates and have ad libitum access to the feed. Further details of the testing procedures are available in the NBCIS Guidelines (NBCIS, 2005).

Traits measured in a centralized test are individual feed intake and body weight on a weekly basis, whilst a series of body measurements such as shoulder height (SH) and scrotal circumference (SCR), are measured at the end of the testing period. Average daily gain (ADG) and average daily feed intake (DFI) can then be calculated for each bull at the end of the testing period.

The dataset consisted of ADG, DFI, SDH and SCR of individual bulls tested between 1990 and 2003, with available weaning weight (WWT) and weaning management group information as well as the weaning weights of their contemporaries (herd-mates). Only those animals coming from a weaning contemporary group with three or more sires in the group were considered for the analysis and all records (weaning and post-weaning) greater than three standard deviations from their own contemporary group mean were eliminated. The final data after editing $(\mathrm{n}=47493)$ consisted of 7364 bulls with WWT and post-weaning traits as well as 40129 WWT of their contemporaries, from 2238 sires and 26984 dams. There were 1421 weaning contemporary groups, 502 post-weaning test groups and 727 herd of origin by year groups. Summarized statistics for the data are presented in Table 1.

Table 1 Summarized statistics for post-weaning traits of beef bulls measured at centralized testing centres and their weaning weights (including their contemporaries)

\begin{tabular}{lcr}
\hline Trait $^{\text {a }}$ (units) & Number of records & Mean (s.d.) \\
WWT (kg) & & \\
ADG (g/day) & 47493 & $228(32)$ \\
DFI (g/day) & 7364 & $1648(244)$ \\
SDH (mm) & 7364 & $10463(1310)$ \\
SCR (mm) & 7360 & $1193(39)$ \\
\end{tabular}

${ }^{\mathrm{a}} \mathrm{WWT}=$ weaning weight (adjusted to 205 days of age); ADG = average daily gain; DFI = average daily feed intake; $\mathrm{SDH}=$ shoulder height; $\mathrm{SCR}=$ scrotal circumference 
Weaning weight was linearly adjusted to 205 days of age and for age of dam by sex classes following the Beef Improvement Federation (BIF) Guidelines (BIF, 1996). Age of dam (in days) was grouped into eight categories, as suggested by Bergh \& Joosten (2004). The model currently used for the national genetic evaluation of WWT in the Bonsmara breed was used to obtain Best Linear Unbiased Estimators of each age of dam class for the two sex of calf classes (i.e. 16 age of dam by sex of calf classes) and the solutions were used to pre-adjust the WWT records. The adjustment factors were comparable to the standard age of dam by sex of calf classes adjustment factors, published in the BIF Guidelines (BIF, 1996).

A series of alternative two-trait analyses was performed to examine the effects of herd of origin by year (HY) and dam (including both maternal additive genetic and permanent environmental effects) on ADG, DFI, SDH and SCR. All two-trait models included WWT along with one of the post-weaning traits measured on test. Weaning weight was included in the analysis of post-weaning traits to account for the within-herd-year component of the environmental carry-over effect on the performance on test (De Rose et al., 1988b). Pollack \& Quaas (1981) indicated that including information from correlated performance to weaning would also account for selection of bulls entering test stations. For ADG, the most complete twotrait model (M1) used was:

$$
\begin{aligned}
& \mathrm{WWT}_{\mathrm{ijk}}=\mathrm{C}_{\mathrm{k}}+\mathrm{G}_{\mathrm{i}}+\mathrm{D}_{\mathrm{j}}+\mathrm{E}_{\mathrm{ijk}} \\
& \mathrm{ADG}_{\mathrm{ijkl}}=\mathrm{T}_{\mathrm{k}}+\beta_{1} \mathrm{X}_{\mathrm{i}}+\beta_{2} \mathrm{X}_{\mathrm{i}}{ }^{2}+\mathrm{HY}_{1}+\mathrm{G}_{\mathrm{i}}+\mathrm{D}_{\mathrm{j}}+\mathrm{E}_{\mathrm{ijk} \mathrm{l}}
\end{aligned}
$$

where in (1) $\mathrm{WWT}_{\mathrm{ijk}}$ is the weaning weight (adjusted to 205 days of age and the age of dam by sex of calf classes); $\mathrm{C}_{\mathrm{k}}$ is the fixed effect of the $k$ th weaning contemporary group (herd + weaning date + management code); $G_{i}$ is a random direct additive genetic effect of the $i$ th animal; $D_{j}$ is the random dam effect (genetic + permanent environmental) of the $j$ th dam; $E_{i j k}$ is the random residual effect, and in (2) ADG $_{\mathrm{ijkl}}$ is the bull's post-weaning average daily gain on test; $T_{k}$ is the fixed effect of the $k$ th test group (test centre + test number + test year); $\beta_{1}$ and $\beta_{2}$ are the linear and quadratic regression coefficients of the age of the $i$ th bull $\left(\mathrm{X}_{\mathrm{i}}\right)$ on test; $\mathrm{HY}_{1}$ is the random effect of the lth herd of origin by year group; $\mathrm{G}_{\mathrm{i}}$ is a random direct additive genetic effect of the ith bull; $\mathrm{D}_{\mathrm{j}}$ is the random dam effect (genetic + permanent environmental) of the jth dam; $\mathrm{E}_{\mathrm{ijk}}$ is the random residual effect. Random effects G, D, HY and E were assumed to be uncorrelated with each other within traits, and their covariance matrices were equal to $\mathbf{A} \sigma_{\mathrm{g}}^{2}, \mathbf{I} \sigma_{\mathrm{d}}^{2}, \mathbf{I} \sigma_{\text {hy }}^{2}$, and $\mathbf{I} \sigma_{\mathrm{e}}^{2}$, respectively, where $\mathbf{A}$ is the Wright's numerator relationship matrix and $\mathbf{I}$ is the identity matrix of appropriate orders. All random effects were assumed correlated between traits.

Although a more traditional approach would be to fit the HY as a fixed effect, the HY effect on postweaning traits was fitted as random in order to estimate its variance. The data structure had many small HY groups and too much information would be lost if it was treated as a fixed effect. Furthermore, genetic evaluation of post-weaning traits would likely involve an even larger proportion of small HY groups, which would make fitting HY as a fixed effect unfeasible (Schenkel et al., 2004).

A further traditional approach of accounting for maternal effect for weaning weight would be to fit both maternal additive and permanent environmental effects. However, in the current analysis, a random dam effect was fitted in the place of maternal additive and permanent environmental effects for both weaning and post-weaning traits to create a more sparse system of equations, enhancing the analysis (Schenkel et al., 2004).

The most complete two-trait models (M1) for DFI, SDH, SCR with WWT were similar to the model described above. The second set of two-trait models (M2) did not include the D effect for post-weaning traits, and the third set (M3) excluded the HY effect for post-weaning performance traits in Eq. (2). The models were compared based on the likelihood ratio test statistic (LRT). The LRT has a chi-square distribution with the degrees of freedom equal to the difference in the number of parameters between the full and reduced models. The critical value can usually be obtained from a chi-square table. Based on the results of the LRT test, a multiple-trait animal model which included WWT, ADG, DFI, SDH and SCR was used to estimate (co)variance components for weaning and post-weaning traits on test. All analyses were carried out using the VCE package developed by Groeneveld (1994).

The resulting variance components were used to estimate breeding values (EBVs) for all the animals in the entire Bonsmara database $(n=1045$ 142) using the multiple-trait models including or excluding the HY effect on the post-weaning traits. Spearman's rank correlation was computed between the two sets of 
EBVs (with and without the HY effect) for ADG, DFI, SDH and SCR considering different proportions of selected sires: all sires, top $10 \%$ of all sires, and top $1 \%$ of all sires.

\section{Results and Discussions}

The LRT was computed between the full model (M1) and other models (M2 and M3) to test for the effects of dam and HY on post-weaning traits on test, and the results for ADG are presented in Table 2. The importance of the D effect on ADG was evaluated by comparing models M1 and M2. Models M1 and M3 were used to assess the importance of the HY effect. Based on the LRT, the full model (M1) was superior to model M3, indicating an important HY effect in the model for ADG. However, the full model was not superior to model M2, indicating the dam effect was not relevant for ADG. The estimated proportions of variance relative to phenotypic variance also indicated that the dam effect was small and within two standard deviations from zero. Alternative two-trait models for DFI, SDH and SCR also showed the same trend, and consequently the dam effect was excluded from the model for post-weaning traits in the subsequent multipletrait analysis. Schenkel et al. (2004) also indicated the dam effect was not important in the analyses of postweaning performance on test.

Table 2 Model comparisons and estimated proportions of variances (with s.e.) with respect to phenotypic variances using alternative two-trait models for average daily gain (ADG) and weaning weight (WWT)

\begin{tabular}{|c|c|c|c|c|c|c|}
\hline \multirow{3}{*}{ Effect $^{a}$} & \multicolumn{6}{|c|}{ Models $^{b}$} \\
\hline & \multicolumn{2}{|c|}{ M1 } & \multicolumn{2}{|c|}{$\mathrm{M} 2$} & \multicolumn{2}{|c|}{ M3 } \\
\hline & WWT & $\mathrm{ADG}$ & WWT & $\mathrm{ADG}$ & WWT & $\mathrm{ADG}$ \\
\hline \multirow[t]{2}{*}{ G } & $0.22(0.02)$ & $0.47(0.06)$ & $0.22(0.02)$ & $0.48(0.06)$ & $0.22(0.01)$ & $0.45(0.06)$ \\
\hline & & $0.31(0.03)$ & & $0.33(0.01)$ & & $0.40(0.03)$ \\
\hline \multirow[t]{2}{*}{$\mathrm{D}$} & $0.22(0.01)$ & $0.16(0.10)$ & $0.22(0.01)$ & & $0.22(0.01)$ & $0.21(0.15)$ \\
\hline & & $0.04(0.02)$ & & & & $0.03(0.02)$ \\
\hline HY & & $0.09(0.01)$ & & $0.09(0.01)$ & & \\
\hline \multirow[t]{2}{*}{$\mathrm{E}$} & $0.55(0.02)$ & $0.27(0.02)$ & $0.56(0.02)$ & $0.27(0.02)$ & $0.55(0.01)$ & $0.27(0.03)$ \\
\hline & & $0.57(0.03)$ & & $0.58(0.01)$ & & $0.57(0.03)$ \\
\hline$\sigma_{p}^{2}$ & 468 & 41930 & 468 & 41990 & 468 & 40150 \\
\hline $\mathrm{LRT}^{\mathrm{c}}$ & \multicolumn{2}{|c|}{-} & \multicolumn{2}{|c|}{2} & \multicolumn{2}{|c|}{33} \\
\hline \multicolumn{7}{|c|}{$\begin{array}{l}{ }^{\mathrm{a}} \mathrm{G}=\text { additive direct genetic effect; } \mathrm{D}=\text { dam (genetic }+ \text { permanent environmental) effect; } \mathrm{HY}=\text { herd of } \\
\text { effect; } \mathrm{E}=\text { residual effect; } \sigma_{\mathrm{p}}^{2}=\text { phenotypic variance } \\
\text { Ratios are on the diagonal and correlations between traits are off-diagonal } \\
{ }^{\mathrm{b}} \mathrm{M} 1=\text { full model; } \mathrm{M} 2=\text { model without dam effect for ADG; M3 = model without HY effect for ADG } \\
\text { c } \mathrm{LRT}=\text { Likelihood Ratio Test computed between M1 vs. M2 and M1 vs. M3, respectively }\end{array}$} \\
\hline
\end{tabular}

Estimates of variance ratios with respect to phenotypic variance for direct additive $(\mathrm{G})$, dam (genetic + permanent environmental; D), weaning herd of origin by year (HY), and residual (E) effects from a multipletrait animal model of post-weaning traits on test and weaning weight are presented in Table 3 . The proportions of the phenotypic variance attributable to the effect of herd of origin by year were $9 \%, 10 \%, 6 \%$ and $5 \%$ for ADG, DFI, SDH and SCR, respectively. The contribution of the HY effect to the phenotypic variance was $8 \%$ for estimated weight gain on test in the study by Schenkel et al. (2004). Mantovani et al. (1999) analyzed ADG on 940 bulls from a central test station in Italy, and also reported an important effect of herd of origin of the bull. Collins-Lusweti \& Curran (1985), Tong et al. (1986) and Liu \& Makarechian (1993) also reported similar variation due to herd of origin on ADG of bulls on test. Schenkel et al. (2002) used a random regression single-trait analyses and demonstrated the permanent nature of this effect on estimated weight gain on test over the entire testing period. Schenkel et al. (2004) also indicated that the HY variation reported in their study was more likely associated with real pre-weaning environmental effects than other sources of variation such as genetic and maternal effects. 
Table 3 Phenotypic variance and variance $\operatorname{ratios}^{\mathrm{a}}$ for post-weaning traits of beef bulls measured at centralized testing centres and weaning weight (including their contemporaries)

\begin{tabular}{lccccc}
\hline Trait $^{\mathrm{b}}$ & $\sigma_{\mathrm{p}}^{2}$ & $\mathrm{~h}^{2}$ & $\mathrm{~d}^{2}$ & $\mathrm{hy}^{2}$ & $\mathrm{e}^{2}$ \\
\hline WWT & 470 & 0.27 & 0.17 & - & 0.56 \\
ADG & 42630 & 0.34 & - & 0.09 & 0.57 \\
DFI & 109500 & 0.36 & - & 0.10 & 0.54 \\
SDH & 797 & 0.51 & - & 0.06 & 0.43 \\
SCR & 609 & 0.46 & - & 0.05 & 0.49
\end{tabular}

\footnotetext{
${ }^{a} h^{2}, d^{2}, h y^{2}$, and $e^{2}$ are the proportion of phenotypic variance due to direct additive genetic, dam, herd of origin by year and residual effects, respectively. The standard error was 0.01 for all the variance ratios

${ }^{\mathrm{b}} \mathrm{WWT}=$ weaning weight (adjusted to 205 days of age); $\mathrm{ADG}=$ average daily gain; DFI = average daily feed intake; $\mathrm{SDH}=$ shoulder height; $\mathrm{SCR}=$ scrotal circumference
}

The proportions of phenotypic variance attributable to direct additive genetic effect were $0.27,0.34$, 0.36, 0.51 and 0.46 for WWT, ADG, DFI, SDH and SCR, respectively (Table 3). De Rose et al. (1988a) reported heritabilities, averaged across breeds, of $0.25,0.44,0.85$, and 0.53 for pre-weaning ADG, teststation ADG, SDH and SCR, respectively. Maiwashe et al. (2002) analyzed data of Bonsmara bull calves participating in the on-farm growth tests, and reported estimates of heritabilities of $0.29,0.19,0.42$ and 0.46 for WWT, ADG, SDH and SCR, respectively. Schenkel et al. (2002) using a random regression model indicated that the estimate of heritability for gain on test increased over time, being maximum at the end of test (0.38), comparable with the current estimate of 0.34. Schenkel et al. (2004) used two-trait analyses of pre-weaning gain and estimated weight gain on test, and reported heritability estimates of 0.36 for pre-weaning gain and 0.34 for estimated gain on test. The weighted average estimates of heritabilities are $0.24,0.31,0.34,0.61$ and 0.48 for WWT, post-weaning gain, feed intake, yearling height and SCR, respectively (Koots et al., 1994a).

The estimated additive genetic and herd of origin by year correlations among WWT, ADG, DFI, SDH and SCR are reported in Table 4. Estimates of genetic correlations amongst traits were low to moderate, with the exception of ADG with DFI. The high positive genetic correlation (0.73) between ADG and DFI could be unfavourable because selecting for fast growing animals would lead to correlated increase in feed intake. The estimated genetic correlations are well within the range of published estimates (Koots et al., 1994b; Maiwashe et al., 2002; Schenkel et al., 2004). The estimated herd of origin by year correlations ranged from -0.23 to 0.71 .

Table 4 Estimated direct additive genetic (above diagonal) and herd of origin by year (below diagonal) correlations (with s.e.) for post-weaning traits of beef bulls measured at centralized testing centres and WWT (including their contemporaries)

\begin{tabular}{lcccc}
\hline Trait $^{\mathrm{a}}$ & ADG & DFI & SDH & SCR \\
\hline WWT & $0.43(0.04)$ & $0.48(0.03)$ & $0.51(0.03)$ & $0.28(0.03)$ \\
ADG & - & $0.73(0.02)$ & $0.55(0.02)$ & $0.41(0.03)$ \\
DFI & $0.65(0.04)$ & - & $0.50(0.02)$ & $0.24(0.02)$ \\
SDH & $-0.23(0.05)$ & $0.11(0.05)$ & - & $0.43(0.02)$ \\
SCR & $-0.09(0.07)$ & $0.10(0.09)$ & $0.71(0.10)$ & -
\end{tabular}

${ }^{\mathrm{a}} \mathrm{WWT}=$ weaning weight; $\mathrm{ADG}=$ average daily gain; DFI = average daily feed intake; SDH = shoulder height; $\mathrm{SCR}=$ scrotal circumference

Several studies (e.g. Tong, 1982; Tong et al., 1986; De Rose et al., 1988a) indicated the existence of negative residual correlations between pre-test and test performance, especially for weight gain. Schenkel et al. (2004) reported a residual correlation which was not different from zero between weaning weight and 
estimated weight gain on test. In the current study, the residual correlations (with s.e.) between WWT and ADG, DFI, SDH and SCR were $0.28(0.01), 0.30(0.01), 0.50(0.01)$ and $0.25(0.01)$, respectively. These correlations were $0.29(0.01), 0.29(0.01), 0.48(0.01)$ and $0.23(0.01)$, respectively, when the HY effect was excluded in the model for post-weaning traits. The results suggest there is no compensatory gain during the centralized growth tests, after the adjustment period of 28 days, for those bulls that did not perform well during the pre-weaning period within their herds of origin due to management-related limitations.

The impact of including or excluding the HY effect on the genetic evaluation of post-weaning traits was determined by assessing the rank changes among the top sires. Spearman's rank correlations were greater than 0.99 for ADG, DFI, SDH and SCR when all the sires were considered. However, when the top $10 \%$ of all sires were considered, rank correlations were $0.94,0.93,0.97$ and 0.98 for ADG, DFI, SDH and SCR, respectively. Rank correlations were $0.86,0.88,0.91$ and 0.95 for ADG, DFI, SDH and SCR respectively, when the top $1 \%$ of all the sires was considered. These results indicate re-ranking among the top sires, for example, $14 \%$ of the top $1 \%$ of selected sires based on the model including the HY effect would not be selected if the HY effect was excluded in the model for ADG. Mantovani et al. (1999) and Schenkel et al. (2004) found larger changes in rank than in the current study when models with or without the HY effect on post-weaning traits were compared.

\section{Conclusion}

The present study investigated the consequences of excluding herd of origin by year effect on the genetic evaluation of ADG, DFI, SDH and SCR at centralized test centres of young beef bulls in South Africa. Herd of origin by year has an important effect on the post-weaning traits of beef bulls measured at test centres, despite the 28-day adjustment period. A multiple-trait animal model for the national genetic evaluation of post-weaning traits of beef bulls measured at central testing centres in South Africa should include the effect of herd of origin by year, together with pre-weaning information.

\section{Acknowledgements}

We gratefully acknowledge the Bonsmara Cattle Breeder's Society for permission to use their data. The authors are grateful to M.M. Scholtz, J. van der Westhuizen, L. Bergh, M. MacNeil and D.J. Garrick whose comments improved the manuscript. This research is a contribution of the Livestock Business Division (LBD) of the ARC and was partially based upon the work supported by the Red Meat Research and Development Trust (RMRDT) and the Technology and Human Resources for Industry Programme (THRIP) grants.

\section{References}

Amal, S. \& Crow, G.H., 1987. Herd of origin effects on the performance of station-tested beef bulls. Can. J. Anim. Sci. 67, 349-358.

Archer, J.A. \& Bergh, L., 2000. Duration of performance tests for growth rate, feed intake and feed efficiency in four biological types of beef cattle. Livest. Prod. Sci. 65, 46-55.

Bergh, L. \& Joosten, E., 2004. IRIS Training Manual, Module J, Beef. ARC-Animal Improvement Institute, Irene, Pretoria.

BIF, 1996. Beef Improvement Federation Guidelines for Uniform Beef Improvement Programs. Beef Improvement Federation, Oklahoma State University, Stillwater, USA.

Collins-Lusweti, E. \& Curran, M.K., 1985. A note on environmental factors affecting beef cattle performance tests. Anim. Prod. 41, 131-134.

Dalton, D.C. \& Morris, C.A., 1978. A review of central performance testing of beef bulls and of recent research in New Zealand. Livest. Prod. Sci. 5, 147-155.

De Rose, E.P., Wilton, J.W. \& Schaeffer, L.R., 1988a. Estimation of variance components for traits measured on station-tested beef bulls. J. Anim. Sci. 66, 626-634.

De Rose, E.P., Wilton, J.W. \& Schaeffer, L.R., 1988b. Accounting for pretest environment and selection in estimating breeding values for station-tested beef bulls. J. Anim. Sci. 66, 635-639.

Groeneveld, E., 1994. VCE-A multivariate multimodel REML (co)variance component estimation package. Proc. $5^{\text {th }}$ World Congr. Genet. Appl. Livest. Prod. 22, 47-48. 
Koots, K.R., Gibson, J.P., Smith, C. \& Wilton, J.W., 1994a. Analyses of published genetic parameter estimates for beef cattle production traits. 1. Heritability. Anim. Breed. Abstr. 62, 311-338.

Koots, K.R., Gibson, J.P., Smith, C. \& Wilton J.W., 1994b. Analyses of published genetic parameter estimates for beef cattle production traits. 2. Phenotypic and genetic correlations. Anim. Breed. Abstr. 62, 825-853.

Liu, M.F. \& Makarechian, M., 1993. Optimum test period and associations between standard growth rate in station tested beef bulls. J. Anim. Breed. Genet. 110, 312-317.

Maiwashe, A.N., Bradfield, M.J., Theron, H.R. \&. Van Wyk, J.B., 2002. Genetic parameter estimates for body measurements and growth traits in South African Bonsmara cattle. Livest. Prod. Sci. 75, 293300 .

Mantovani, R., Contiero, B., Gallo, L., Carnier, P., Cassandro, M. \& Bittante, G., 1999. The effect of herd of origin on selection of Chianina, Marchgiana and Ramagnola performance tested young bulls. Zootechnica Nutrizione Animale 25, 109-121.

NBCIS, 2005. National Beef Cattle Improvement Scheme Guidelines, Version 2005.1, ARC-Animal Improvement Institute, Irene, Pretoria.

Pollack, E.J. \& Quaas, R.L., 1981. Monte Carlo study of genetic evaluations using sequentially selected records. J. Anim. Sci. 52, 257-264.

Schenkel, F.S., Miller, S.P., Jamrozik, J. \& Wilton, J.W., 2002. Two-step and random regression analyses of weight gain of station-tested beef bulls. J. Anim. Sci. 80, 1497-1507.

Schenkel, F.S., Miller, S.P. \& Wilton, J.W., 2004. Herd of origin effect on weight gain of station-tested beef bulls. Livest. Prod. Sci. 86, 93-103.

Tong, A.K.W., 1982. Effects of initial age and weight on test daily gains of station-tested bulls. Can. J. Anim. Sci. 62, 671-678.

Tong, A.K.W., Newman, J.A. \& Rahnefeld, G.W., 1986. Pretest herd effects on station performance test. Can. J. Anim. Sci. 66, 925-935. 